\title{
The impact of a mobile Personal Learning Environment in different edu- cational contexts
}

\author{
F. J. García-Peñalvo \\ Computer Science Department. Science Research Institute for Educational Sciences (IUCE). GRIAL Research Group. University of Sala- \\ manca. Paseo de Canalejas, 169, 37008 Salamanca, Spain
}

e-mail: fgarcia@usal.es

M. Á. Conde

Department of Mechanical, Computer Science and Aerospace Engineering. GRIAL Research Group. University of León, Campus de Vegazana S/N, 24071, León, Spain

email: mcong@unileon.es

\begin{abstract}
The emergence and application of Information and Communication Technologies in educational contexts imply changes in the tools used to teach and learn. However, this use does not guarantee the success of such processes. For instance, Learning Management Systems are very popular but also very focused on the institution, which means that they cannot take into account all learning that happens beyond the institution throughout learners' lives. Personal Learning Environments and mobile technologies can be a solution to support such lifelong learning, but what happens in them should be taken into account by the institution. This paper presents a service-based framework to make this type of interaction possible, the communication of mobile personal learning environments with the institutional learning platforms. The framework has been implemented as an Android solution and tested by students and teachers. From these tests, it can be seen that the definition of a mobile Personal Learning Environment is possible and its use increases students' motivation.
\end{abstract}

Keywords: Mobile Learning, Mobile Devices, Personal Learning Environments, Android, Web Services, Interoperability

\section{Introduction}

Teaching and learning processes are affected by the contexts in which they are carried out. These contexts provide teachers and learners with different tools to carry out learning activities. Information and Communication Technologies (ICT) represent some of the trends that can be applied to teaching and learning [1]. ICT has affected the way to access the contents, how the interaction is carried out among the different stakeholders, the kind of tools and resources used, etc. [2].

However, whilst it represents an important advance in many contexts, it does not always guarantee success in learning processes [3]. This is mainly because the learners and the institutions use different kinds of technologies and different learning environments are needed, both institutional and personal ones [4].

From an institutional point of view, the tools a user employs to learn are usually provided by the Learning Management System (LMS), which is a very popular and common solution in both industry and academic contexts [5,6]. These environments are focused on course delivery and provide teachers with tools that not only support but also extend the traditional concept of the classroom and facilitate managerial tasks [7]. These systems also provide students with spaces in which they may perform their academic activities, complement their lectures and, to a greater or lesser extent, collaborate with other students and teachers. However, learners do not only learn in such official contexts and only with institutional applications, nor in specific periods such as academic courses; they learn throughout their lives, using tools that are not provided and controlled by the institution $[8,9]$.

To represent these other ways of learning, including the personalization capabilities that belong to the current digital age in which we live, the Personal Learning Environment (PLE) concept is defined. PLEs facilitate users' learning process, allowing them to use those tools they want and not binding them to a specific institutional context or learning period as the traditional LMS does [10]. The implementation of this concept is not an easy task because the PLE should include very different tools and they should coexist and interact with existing LMSs, especially to provide information about other learning activities that the learners may carry out. However, the learner does not use just different tools, but also different technologies such as mobile devices.

Mobile technologies are quite popular nowadays, something shown by the fact that in 2013 there were more than 6800 million mobile subscriptions all over the world and more than one mobile phone per person in the developed countries [11]. These kinds of devices have evolved very fast; most of them provide access to the Internet and to a great number of services that can be used for different purposes. Thus, mobile devices open new possibilities to carry out learning activities and one of them is to implement a PLE in a mobile device, which is known as an mPLE. 
However, regardless of the PLEs' underlying technology, they should interact with the LMSs. Both types of environments may coexist because they support two different concepts of learning (one controlled by the institution and the other focused on the learner) and also because institutions have already invested great amounts of money and time in the deployment of LMSs and have gained a lot of experience in their use [4]. The likely coexistence of LMSs and PLEs introduces a requirement for interoperation between the two contexts that should be taken into account in Web and mobile platforms. Thanks to this interoperation it would be possible for the learner to access institutional learning activities through mobile devices (which means he/she does not need to go to other contexts) and it would be possible to take into account what the learners carry out in contexts outside the institution, that is, informal learning experiences.

Given this context, it is necessary to define a solution that affords learners the opportunity to include and use the tools they want for learning, including both institutional and non-institutional applications. In addition, it should be possible to return to the LMS the information about what is happening with these tools in the mPLE context. With this aim, the present contribution presents a mobile PLE based on Android technologies and an interoperability framework.

To describe this solution the paper is structured as follows. Section 2 presents the context of this research. After that, in Section 3, the paper describes the solution approach, the interoperability framework, how the mobile device is connected with the LM and shows the Android implementation of the solution. Section 4 presents the result of the evaluation of the implementation through several pilots. Finally some conclusions are presented.

\section{Research context and related works}

The present works deals with the definition and implementation of a mobile Personal Learning Environment. In order to understand it properly it is necessary to take into account what a PLE is.

The definition of a PLE is not easy, and although the term was coined around 2001, there is still debate about it [12]. There are different definitions; some of them are focused on technology and others on pedagogy.

One possible definition of a PLE taking into account both perspectives is the following: A PLE should be understood as a concept, a learning environment focused on the user and customizable, which will combine all the tools, services, opinions, people, resources and activities that are useful in the learning process. This environment should take into account the different training modalities, facilitate lifelong learning and allow the integration of new technologies. From a technological point of view, a PLE can be implemented as an integration framework that incorporates 2.0 technologies, supports interaction with other learning contexts, facilitates interoperability with other existing systems (such as learning content and resource repositories and LMSs) and provides monitoring systems for learners' activities [13].

Mobile PLEs, which are the focus of this paper, can be understood as PLEs represented in mobile devices that provide learners with access to different services and tools through these devices.

Having explained these concepts it is necessary to explore the existing previous works related to mobile PLEs.

Regarding this issue, some trends consider that the mobile device is a PLE in itself. No kind of adaptation or information or functionality is necessary, because the new devices provide by themselves the tools and frameworks that allow learners to personalize their learning [14-16]. In addition, these devices are specially adapted to facilitate informal learning activities carried out away from the institutions [17-19]. This idea is correct but the integration of the tools the students use to learn is not so clear because they are not in the same space and the tools that are valid in one context do not always work in others [20], which can mislead the learner in her ultimate goal, to learn. In fact, authors such as Van Harmelen [21] believe that the PLE should provide a single access point to a variety of learning resources.

There are several initiatives for mobile devices in this sense. An example of these mPLEs was the implementation carried out by Sharples, Corlett and Westmancott [22]. They present the design implementation and evaluation of a handheld device. It is the result of a proof of concept and facilitates the definition of a personal environment in which a child can organize their learning resources, associate it with the learning resources, and share it with learners and teachers. Another example is the MILP (Mobile Information and Learning Platform) [23]. This is a mobile Ajax solution, which allows flexible aggregation of microcontent in tag maps and topic trees. Besides collecting and connecting contents, the MILP provides support for different kinds of interaction and resources. The problem with these approaches is that they do not evolve easily because they have been defined using specific solutions.

Other mPLE approaches define tools to learn using the specific capabilities provided by the devices (GPS, camera, accelerometer, etc.). Some good examples are: the CONTSENS Project [24]; a Mobile Personal Environment helping students to communicate among themselves and with experts by using their mobiles [25]; and experiences of learning languages by using mobiles and taking into account the context of the user [26]. The problem with these solutions is that they depend greatly on the hardware and software of the devices (although software dependences are being solved because of the popularity of some operative systems such as Android and iOS, and other technologies such as HTML5 or widget-based solutions).

On the other hand, there are many projects that use mobile devices as PLEs by including learning functionalities and institutional tools with them. Two representative examples are the MOLLY project [27], a free open initiative integrated with the Sakai LMS, which allows students to make contact with experts, to access academic podcasts and libraries and to obtain information related to an institution; and CampusM, a mobile application that provides different tools to each student adapted to his/her needs (internal messages, blogs, portfolios, maps, calendars, alerts, etc.) and that allows integration with LMSs like 
Moodle or Blackboard [28]. The main drawback of these kinds of solutions is that they are too specifically defined for an institution in a technology, although this can be solved through the use specifications and standards.

There are also some interesting initiatives to define PLEs such as Elgg, which has released mobile versions in order to make an easy way to build PLEs and access them through mobile devices possible [29]. With this system it is possible to access virtual communities defined with Elgg from a mobile device, but this tool is not always enough to define a PLE because it should be enriched with other learning tools and has no way of communicating with the LMSs. Another example of these initiatives is the use of Liferay as a PLE [30].

Moreover, it is also possible to use widget-based solutions to define a PLE in other contexts. In this sense, there are several initiatives such as Aplix Web Runtime [31], the Widget run-time: WAC-1.0 Compliant Golden for Android [32] and the consortiums between different companies to define common interfaces for mobile applications [33]. The problem with these solutions is that not all of them use standards to define widgets, so they are not a valid solution in platforms different from that for which they are defined. Also some of those widgets can be adapted to be represented as native mobile applications or to an HTML5.0. The drawback in this case is that the teacher or person in charge of the institution has to take into account what is happening in two different contexts.

Last, but not least, it is possible to use LMS native tools from the mobile device, in a way that these tools can be combined with the device's own tools. These are very common solutions implemented by most LMSs [34-41]. These LMS adaptions can be combined with other tools of the mobile device to carry out learning activities. The problem with these initiatives is that they are closely linked to the institution and it is not easy to integrate additional functionalities into the mobile PLE and to combine them with other tools.

All these solutions show that it is possible to open the PLE to other contexts and that it is possible to represent it in a mobile device. However, the heterogeneity of communication interfaces, software and hardware, and the lack of control over the activity, hamper the definition of real independent PLEs.

Another problem with most of these solutions is how to facilitate communication with the institutional environment. It is necessary to track the activity that is carried out on the mobile device so that it can be taken into account [42-44]. Moreover, it is interesting that a mobile PLE can be enriched with institutional activities so the learners should not need to use two different environments to learn. These facts show the need to facilitate the interoperation between institutional and personal learning environments.

In this sense, Wilson and others proposed three possible scenarios of interoperability between the LMS and the PLE [45]. However, only the second one, which considers opening the LMS by using Web services and interoperability initiatives, is interesting for this research. This integration trend includes: iGoogle-based initiatives [46], social networks connected with LMSs [47], LMSs that offer support for implementations of interoperability specifications [48], PLEs with specific communication protocols [21] or integration based on service-oriented architectures - SOAs [49]. Two main difficulties for these initiatives are: institutional barriers to the opening of formal environments and the fact that those initiatives are focused on information exportation and not on interaction exchange. That is to say, communication is oriented in one direction, from the LMS towards the external tools.

However, as mentioned above, the interoperability should not be only in one direction; it is important to integrate the results of what has happened in the mPLE so that this information can be used. Regarding this, there are different possibilities. For instance, it is possible to return information about what is happening through a Twitter channel [50], store logs about what is happening to exploit them with analytic tools [19], define a tracking module included in the PLE [50], etc. The problem with approaches like these is that teachers and people in charge of the institutions, in order to see what has happened in the mPLE, should access other environments, or an extra effort is needed to integrate external tools in the institutional environment.

Taking all these solutions into account, with their problems and how they are faced, a possible solution could be based on the definition of mPLE that uses Web services and interoperability specifications to facilitate the interaction with the institutional environments. This mobile PLE should be a framework that facilitates the use of tools integrated in the mobile and others that represent institutional functionalities. The results of the user activity should be returned to the institutional environment by using the interoperability specifications. 


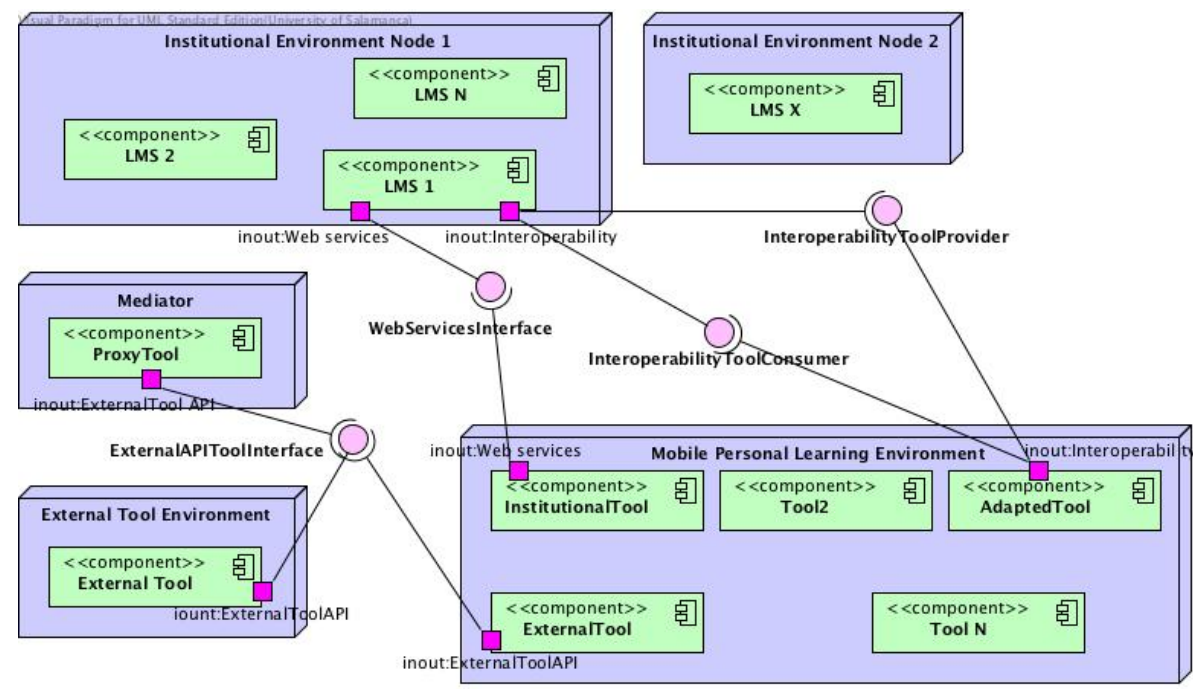

Fig. 1. Deployment diagram of the framework.

\section{Proposal for a mobile PLE}

This section presents a service-based framework to communicate the mPLE with the LMS. It also describes how the mPLE is implemented as an Android application as a proof of concept.

\subsection{Interoperability framework}

The need for interoperability between the MPLEs and the LMS learners requires definition of the communication ways between such tools, in such a way that the activities carried out in the devices can be taken into account by the institutional environments. Taking this into account, the mPLE can be understood as a set of mobile services, tools and communication channels that make it easy for the learner to carry out learning activities outside of the institutional environment with the possibility of returning to it the outcomes achieved.

In this sense, the authors of the paper have defined a service-based framework that, by using Web services and interoperability specifications, facilitates the definition of a PLE with activities that return information to the LMS [51]. This framework includes a mobile device that by using Web services would include into it an institutional activity. However, the framework did not consider how a mobile PLE could really work, and therefore the framework has been adapted (Fig. 1).

The LMS is the basic tool of the institutional environment. Each node can include one or several LMSs and the framework does not define the number or the specific LMS to use. However, the LMSs should satisfy a minimum set of requirements; they should support Web services and interoperability specifications. By supporting Web services, the LMSs will be able to export functionalities from the institutional side to the mPLE and in this way the learners can use them from a different environment, which means that they do not need to access the LMS if not necessary and could use just one learning environment. On the other hand, by supporting interoperability speeifications it would be possible to return information about what is happening in the mPLE to the LMS.

Fig 1. presents how the LMS implements a Web service interface (WebServicesInterface) that is consumed by the mPLE in order to access institutional functionalities. Fig 2. shows an example of this process modelled by using BPMN (Business Process Modelling Notation) [51]. The diagram shows that the mPLE requests a service from the LMS, which, having received the request, processes it, executes the service and returns the results, which will be shown on the mobile device.

In addition, the LMS implements an interface to be able to launch external activities into the mPLE (InteroperabilityToolConsumer); and it uses the interface implemented by the tools (InteroperabilityToolProvider) to integrate the outcomes of what happens in the mPLE. 


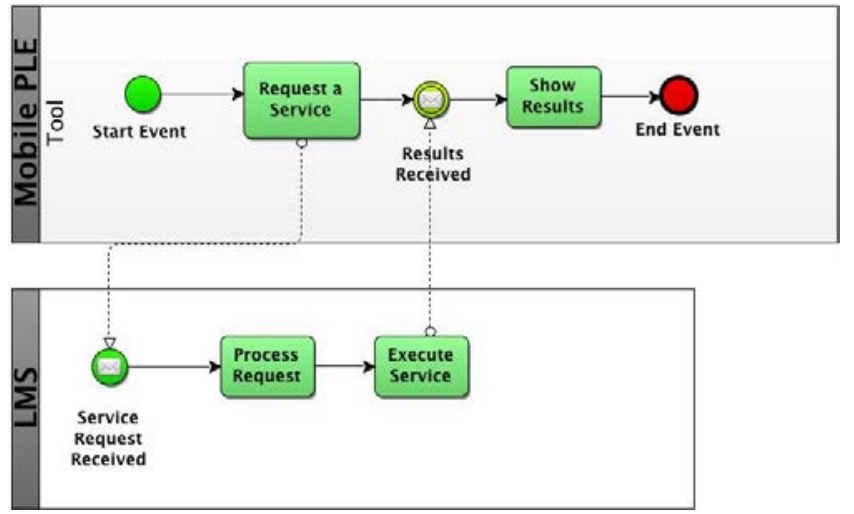

Fig. 2. BPMN diagram that describes how Web services are consumed from the PLE and provided by the LMS.

Other important elements are the tools included in the mPLE. These are the tools that the learner may use to learn in his/her personal environment defined on the mobile device. There are three types of tools:

- Tools that do not interact with the LMS. These are tools that can be employed in learning activities, but in order to take into account what the user does in them, the teacher should leave the LMS, enter the tool and check the activity carried out. That is any tool of a mobile device that can be used for educational purposes. For instance, the use of Instagram on the mobile device.

- Tools that use the LMS Web services layer. These kinds of tools use the Web services provided by the learning platforms in order to access information and functionalities from outside of this environment. Such tools should include a Web service consumer that uses the Web service interface provided by the LMS. For example, an adaptation of the LMS forum that can be used on the mobile.

- Tools that can integrate the students' activity through the use of interoperability specifications. These tools, which implement interoperability specifications, can be set up and instantiated as learning activities by the teacher in the LMS. In this way, the student may use them on the mobile device and it is possible to return the learners' outcomes achieved in this context to the LMS. The teacher does not need to access other contexts to check what the learner has done.

It should be noted that a tool could consume Web services and at the same time act as an Interoperability Tool Provider by using interoperability specifications.

In addition, the framework includes other kinds of components. They are the mediators, also known as Proxy Tools. These components facilitate communication between the tools and the learning environments. They have two main aims. The first one is to facilitate the interoperability with tools that cannot implement a Tool Provider. This means tools that cannot be accessed to modify the source code. In this case, the mediator interacts both with the tool by using the interfaces that they provide (ExternalToolAPI) and with the LMSs. The other aim of the mediator is to provide additional functionalities or preprocess data. For example, it can be used to provide an interface to evaluate learners' activity in tools that are included in the mPLE but were not thought of as learning tools, such as GoogleDocs.

\subsection{Implementation of the framework and the mobile solution}

In order to check the suitability of the MPLE both the framework and the mobile solution are implemented as a proof of concept. This implementation consists of:

- Institutional context. Although different LMSs could be used, several Moodle 2.1 instances were used in the proof of concept. There are different reasons for using Moodle in this context. Apart from the fact that Moodle is one of the most popular LMSs all over the world, it is also: 1) open source; 2) developed and supported by an international community with more than 1,000,000 members [52]; 3) a system with more than 68,000 installed servers in which there are more than 58 million students; 4) translated into more than 75 languages [53]; 5) very successful in different institutions [54]; and 6) it includes a Web service layer that opens it to new technologies and facilitates it being integrated with service-oriented architectures $[55,56]$.

- Communication channels. In order to implement these channels, Web services were used to exchange information and interaction with the LMS and BLTI [57] to integrate the students' activity performed in other environments and to guarantee the portability of the framework to other contexts. The Web services will be those provided by the LMS, which can be extended by following the Moodle extension protocol if needed. However, it is not possible only to use Web services because this would mean that the framework should be adapted to the service layer of each learning platform to be used. This was solved by using BLTI, implemented by most LMSs [48].

- The Mobile Personal Learning Environment. There were several possibilities for implementing the mobile PLE. It can be implemented as a widget container with different widgets representing the tools. This kind of solution facilitates the representation of the applications not only in a mobile context, but also in a browser or on a computer desktop. The main prob- 
lem with this is that the existing mobile run-time containers are beta products and some widgets do not work properly and such containers are linked to a specific mobile operating system (there is a version for Android, another for iOS, etc.).

Another possibility was to use Web services to connect an HTML5 [58] solution. In this way, it is possible to represent the mobile device independently of the device. The problem with this solution is that it is joined to a specific LMS, which means that it is not easy to include other tools. In addition, an HTML5 solution does not allow the learner to add any tool he/she uses to learn.

Both solutions can be combined in order to define a mobile version of the LMS by using HTML5 and include also some tools represented by widgets [59]. However, this can mislead the learner, who would have various entry points to learning in their devices.

Taking this into account, for the implementation the research team decided to use a specific mobile system, Android. This is one of the most popular mobile operating systems and, although this constrained the solution by a specific technology, it facilitated a free, open and scalable definition of the mobile PLE.

In order to carry out this implementation, first a container is defined. It gives access to the user to the different tools included in the PLE (Fig. 3). In addition, it allows the learner to add any tool installed on the phone and facilitates downloading and installing others.

They can be institutional tools adapted to the mobile that uses the LMS Web services interface; and also other tools that, by using interoperability specifications, return the outcomes of the learners' activity in the mobile environment. For the proof of concept two tools were adapted for the mPLE. One of them was a Moodle forum. This represents how an institutional tool can be accessed through the mobile PLE and the activities that take place are reflected in the LMS (Fig. 4). With this tool the learner can read his/her forums in Moodle courses, create discussions, posts, etc.

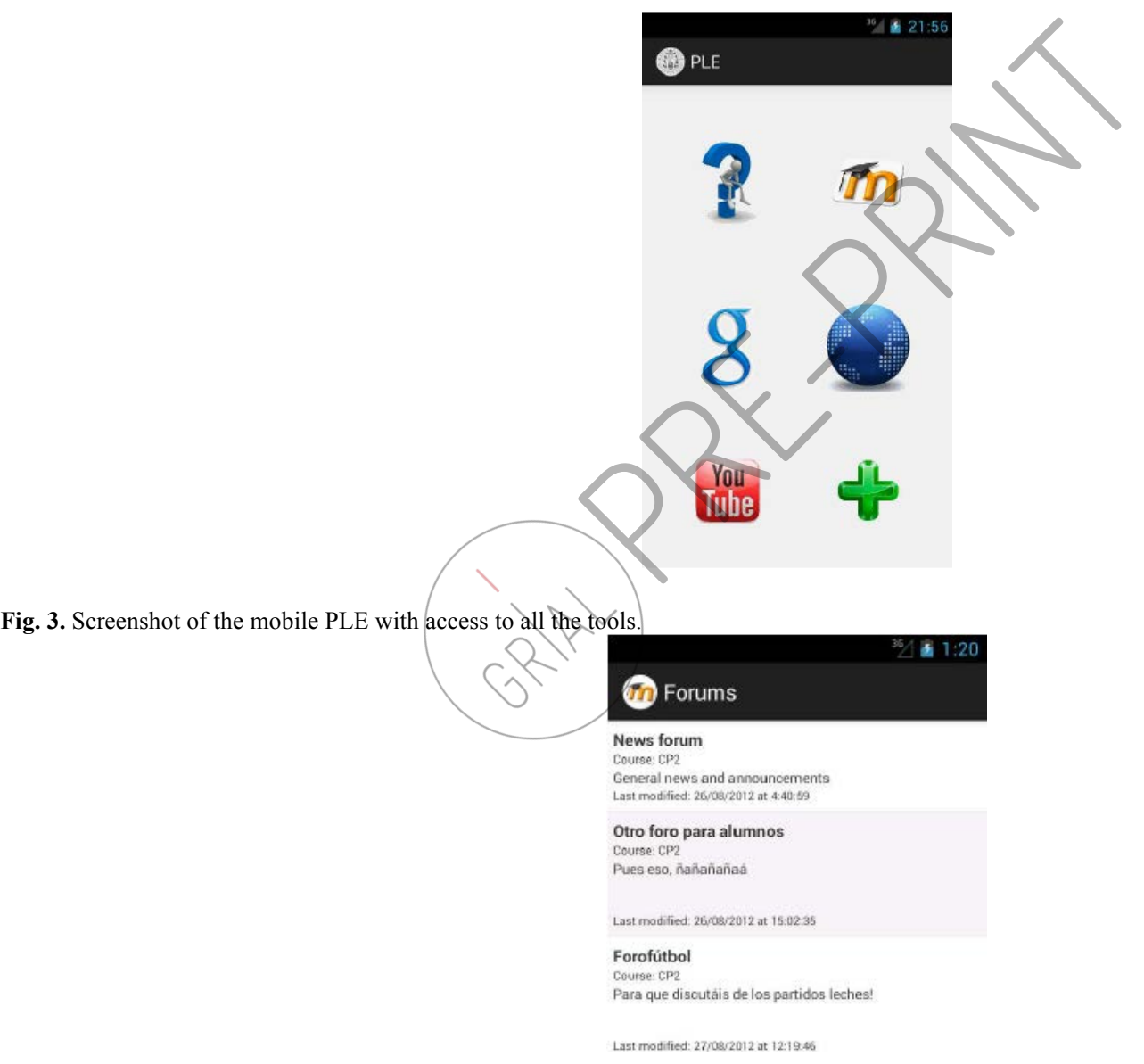

Fig. 4. Screenshot of the forum application on the mobile PLE.

An example of the interaction with the forum is shown in Fig. 5. It shows a BPMN diagram that describes how the mobile forum tool consumes Moodle Web services in order to show the list of forum discussions to a user. The user requests the list of discussions; this request is received and preprocessed by a RequestHandler (this means that the arguments are extracted from the messages, something done in a different way depending on the Web services implementation, e.g.: SOAP, REST, JSON-RPC). After that, the content of the request is sent to the request processor. It checks the user identity. If he/she does not have permission to get the discussion list, a response will be sent with an error; on the other hand, if the us- 
er is allowed to gather the information, the discussion list will be returned following the Web service model used in the request. Once these data are in the forum tool they are shown to the user.
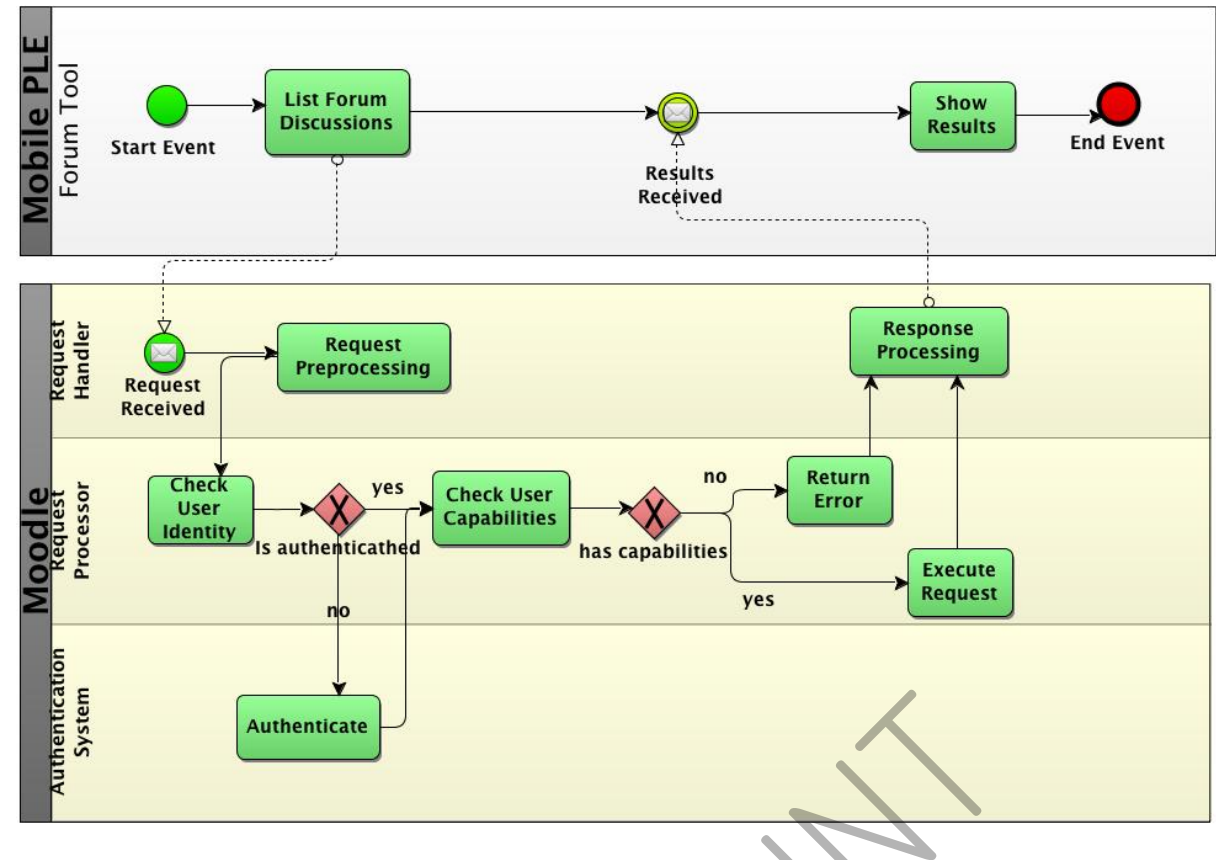

Fig. 5. BPMN diagram that shows how the mPLE and the LMS exchange information through the Web services to list the discussions in a forum.

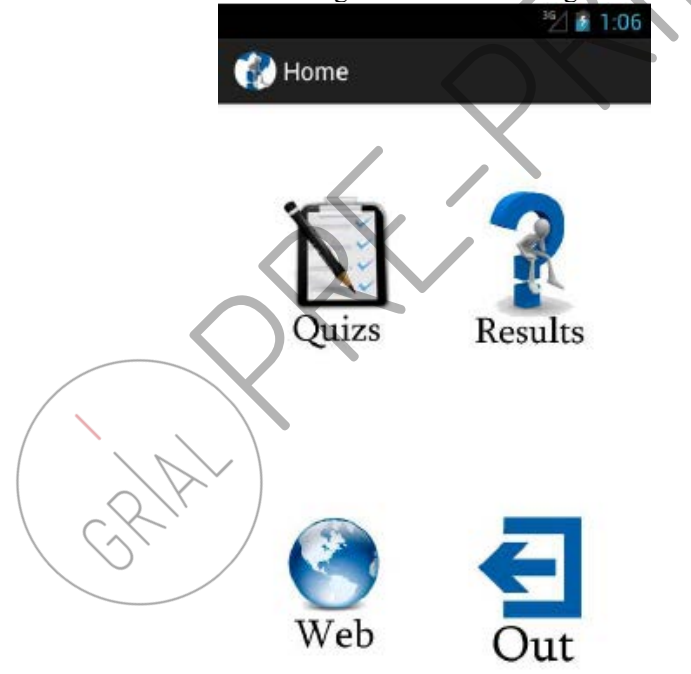

Fig. 6. Mobile Quiz tool in the Mobile PLE

The other tool adapted to the mPLE uses interoperability specifications to return learners' outcomes to the LMS. It is a quiz tool; the learner can answer quizzes and return the results to the LMS (Fig. 6). The teacher in Moodle instantiates a quiz-based activity and the learner can access it through his/her mobile and complete the quizzes.

The main advantage of this type of implementation is that it provides the learner with a single access to all the tools and services he/she uses to learn in an mPLE, independently if they are functionalities exported from the LMS, external tools, services of the mobile device, etc. This also means that it is possible (although it was not included in the proof of concept implementation) to track the activity that learners carry out in mPLE and return it to teachers and people in charge of the institutions so they can make decisions. For instance, if the teacher detects that students are using the YouTube tool to access videos while learning, they may propose some videos, record and publish solutions in order to improve students' learning.

Given this implementation of the mPLE and the framework there are different possibilities for interaction between the mPLE and the LMS. One of them is evaluated in the next section: the integration of institutional tools in the mPLE. 


\section{Research Model and Methodology}

In order to evaluate the validity of the framework and how the integration of institutional tools can be done in the PLE a pilot was carried out. Validation is done through an empirical exploratory experiment with a small sample of students and teachers. It involved '56 third-year students from the Evaluative Research in Education degree course and four teachers.

This exploratory experiment aims to validate the research hypothesis defined by taking into account the adaptation of the interoperability framework and the definition of mPLE. This hypothesis may be formulated as follows: "The students appreciate as a positive asset the use of institutional functionalities on a mobile device, which helps them to learn."

The idea behind this experiment is to validate the research hypothesis by taking into account students' and teachers' perceptions of the use of the mPLE and how it helps them to learn. In order to do so, both qualitative and quantitative techniques are applied. This is known as mixed research methods, and may help provide a more complete overview of the phenomenon and study validation [60]. In the case of learners, quantitative techniques were used - a pilot was carried out, with data gathered through surveys. However, teachers' perceptions were evaluated by means of a semi-structured interview after their experience with the system, followed by a survey, which included open questions for qualitative analysis.

Quantitative validation required a quasi-experimental design [61]. The reason for this is that, in this experiment, pre-established groups of students - class groups - were used, and therefore it was not possible to have random groups of people. Participants were divided into an experimental group - students using the system - and a control group - students who did not use the system.

Quasi-experimental design implies the definition of a scientific hypothesis, from which a dependent variable is derived. Such a variable is operationalized through several assertions, which are proposed to the students of both the experimental and control groups. The students graded these assertions by using a five-point Likert scale (from 1, corresponding to strongly disagree, to 5 , strongly agree).

In both groups the same tests were applied - a pretest at the beginning of the experiment and a post-test after it - but the students from the experimental group tested the mPLE, while the people in the control group did not. After running the experiment, data were analysed by using probabilistic techniques to validate the scientific hypothesis.

The scientific hypothesis is accepted if the results of the pretest are similar in both groups - which proves that both groups have a common knowledge and background - but the results of the post-test are different for both groups, i.e. those who have tested the tool should have different perceptions about the use of the tool.

For the current pilot a dependent variable derived from the scientific hypothesis is: the impact of the use of institutional functionalities through mobile devices.

In order to operationalize this dependent variable, students were asked about their level of agreement with different statements (see Appendix A) about the system before and after using it - pretest and post-test stages, respectively.

In order to confirm whether there are differences between the pretest and post-test results, two statistical tests were applied: a Student's T-test and the non-parametric Mann-Whitney U test. The second one was used to confirm the results of the first, since the lower limit for the application of a Student's T-test is around 40 people. In addition, the Mann-Whitney U test is recommended for ordinal scales [62], such as the one used in this study.

For a Student's T-test, a null hypothesis is presented for each item; null hypothesis acceptance means that there are no significant differences between experimental and control groups $\left(\boldsymbol{H}_{0}: \overline{X_{E}}=\overline{X_{C}}\right)$. Null hypothesis is accepted if the bilateral significance of the item is under 0.05 ; otherwise, the null hypothesis is rejected. On the other hand, the Mann-Whitney U test is based on a range comparison between the experimental and the control group and in this case the null hypothesis is $H_{0}: \overline{R_{E}}=\overline{R_{C}}$ (i.e. the range of the experimental group is equal to the control group). As with the T-test, signification should be greater than 0.05 to accept the null hypothesis. Additionally, students were asked their opinion about the export of Moodle functionalities and about learning through mobile devices and the combination of different tools (see Appendix A). These techniques are also used to compare the results of the current research with other previous ones.

Teachers' opinions were also assessed by means of semi-structured interviews, and also by answering a survey (items are shown in Appendix A); their responses were gathered through a form, which therefore allowed a qualitative analysis supported by quantitative data. The qualitative analysis is based on open questions related to teachers' opinions about how the mPLE contributes to facilitating students' learning and whether it motivates them and increases their participation. After analysing the text of the answers provided by the teachers, the responses were grouped based on topic-proximity criteria. In this case the group units were exporting (of LMS tools), combination (in the MPLE with other tools the learner may use to learn outside the institution), participation (how the use of the mPLE affects students' course participation) and problems (if these two environments may cause some kind of conflict for learners). The results from this analysis were shown in a matrix in order to be able to extract conclusions from that information [63]. Fig. 7 depicts the research model and the methodology.

\section{Results and discussion}

The sample for the pilot comprised 56 students, so it was possible to apply both the Mann-Whitney U and the Student's T-test. The results of the Mann-Whitney U test were similar in both tests. These students were divided into two groups. The control group has 33 students and the experimental group 23. The division was done on the basis of the class groups' distribution. 
The results of the Student's T-test are shown in Table 1. Each row represents an item or statement - identified by their ID in the DV column - and includes the average value for the experimental and control groups $\left(\overline{X_{E}}\right.$ and $\left.\overline{X_{C}}\right)$, the standard deviation for the experimental and control groups $\left(S_{X_{E}}\right.$ and $\left.S_{X_{C}}\right)$, the contrast variable (t) and the bilateral signification $(\rho)$.

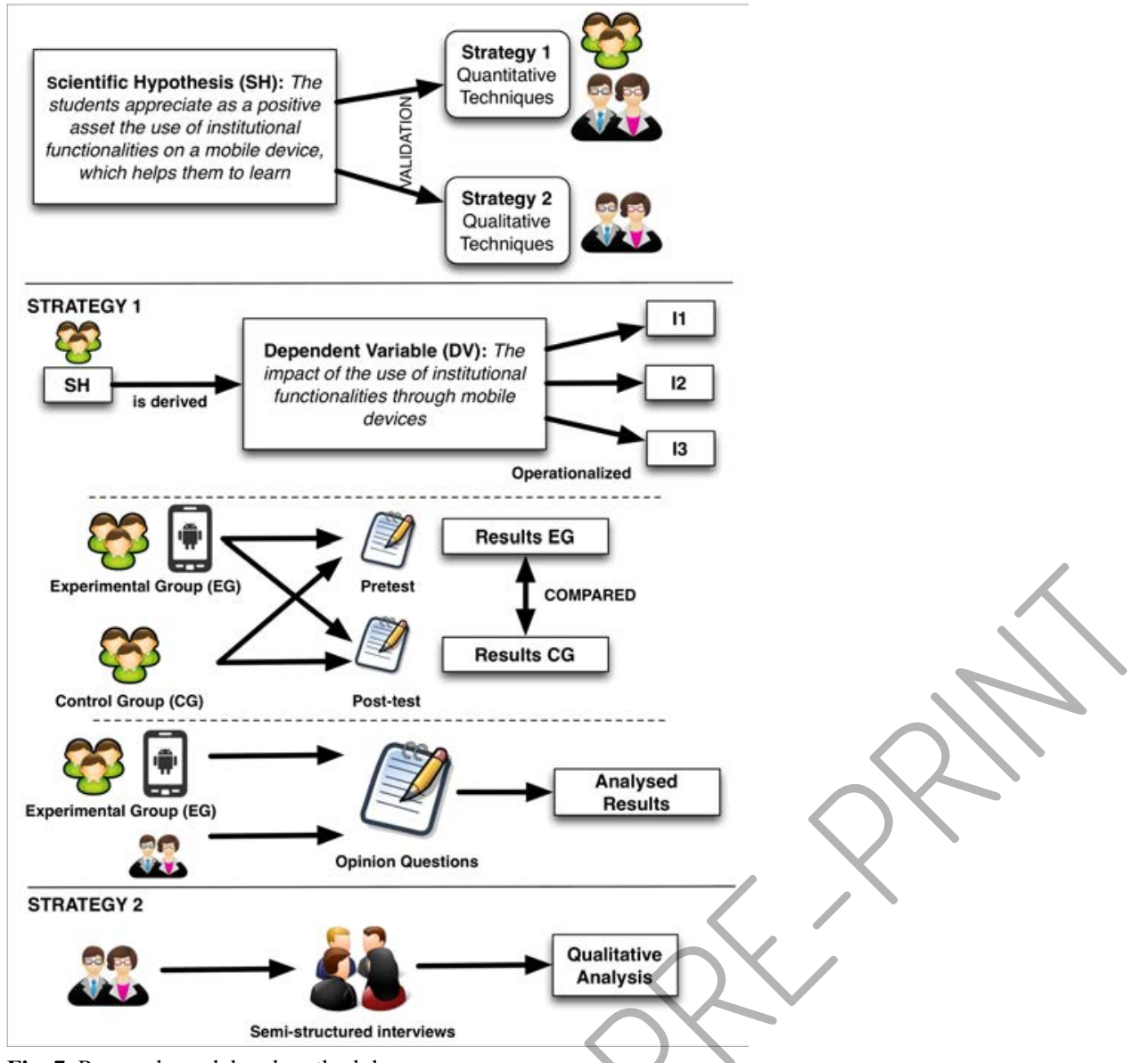

Fig. 7. Research model and methodology.

From these values it can be observed that in both pretest items (I1 and I2) the null hypothesis is retained (that is, the experimental and control group answer more or less the same) with a bilateral signification of 0.768 and 0.322 , which is greater than 0.05. In the post-test the null hypothesis is rejected (the results between the experimental and control group are different). It should be noted that in item I1 and item 12 the average for the experimental and control groups is between 2 and 3, which means that most of them do not use mobile devices to access Moodle or other learning tools. It is also interesting to consider the average of the experimental group in the post-test (4.26), which shows that the students who tested the system consider it useful for learning. These results are confirmed by those from the Mann-Whitney U test. They are shown in Table 2.

Table 1. Results of the Student's T-test.

\begin{tabular}{lccccll}
\hline \multicolumn{2}{l}{ T-test pretest results } & & & & \\
\hline DV & $\overline{X_{E}}$ & $S_{X_{E}}$ & $\overline{X_{C}}$ & $S_{X_{c}}$ & t & $\rho$ \\
\hline I1. & 2,91 & 1,240 & 2,82 & 1,131 & 0,297 & 0,768 \\
I2. & 3,13 & 1,217 & 2,82 & 1,103 & 0,999 & 0,322 \\
\hline T-test post-test results & & & & \\
\hline I3. & 4,26 & 0,689 & 3,27 & 1,039 & 3,986 & 0,000 \\
\hline
\end{tabular}

Table 2. Results of the Mann-Whitney U test.

\begin{tabular}{lllll}
\multicolumn{4}{l}{ Results of the Mann-Whitney U test (pretest) } \\
\hline DV & $\overline{R_{E}}$ & $\overline{R_{C}}$ & $\bar{U}$ & Signification \\
\hline I1. & 29,28 & 27,95 & 361,500 & 0,757 \\
I2. & 31,33 & 26,53 & 314,500 & 0,260 \\
\hline
\end{tabular}




\begin{tabular}{lllll}
\hline \multicolumn{4}{l}{ Results of the Mann-Whitney U test (post-test) } \\
\hline I3. $\quad 37,30$ & 22,36 & 177,000 & 0,000 \\
\hline
\end{tabular}

In it, each row represents an item or statement -identified by their ID in the DV column - and includes the average range for the experimental and control groups $\left(\overline{R_{E}}\right.$ and $\overline{R_{C}}$ ), the Mann-Whitney U variable variable $(\bar{U})$ and the signification.

As with the Student's T-test, the experimental and control groups show no significant differences for the pretest but are significantly different in the post-test. In the pretest, range values are similar, with a signification greater than $0.05-$ and therefore the null hypothesis is accepted. In the post-test the signification level is under 0.05 , which means that the null hypothesis is rejected and the experimental and control groups have a different perception after the experience.

Since the results of the pretest are similar for the experimental and the control groups, but different in the post-test for both groups, it can be concluded that, from the students' perspective, the research hypothesis is confirmed; that is, that for the students it is positive to have the possibility of including institutional functionalities in their mPLE and combining them with other mobile tools.

The answers to the additional question posed to the students support this conclusion (see Appendix A): 95 per cent of the students agree or strongly agree that the exporting functionalities from Moodle, such as the forum to their devices and combining them with other tools, help them to learn.

Regarding teachers' opinions, qualitative and quantitative techniques were used. The results are shown in Table 3.

Table 3. Results of the text analysis grouping the text by the units defined. The units are in the header of the table, EX means export, COMB combination with other tools, PART learners' participation and PB problems.

\begin{tabular}{|c|c|c|c|c|}
\hline & EX & COMB & PART & PB \\
\hline $\mathrm{T} 1$ & $\begin{array}{l}\text { Great } \\
\text { potentiality }\end{array}$ & Useful & $\begin{array}{l}\text { Increased } \\
\text { motivation }\end{array}$ & $\begin{array}{l}\text { Loss of atten- } \\
\text { tion }\end{array}$ \\
\hline $\mathrm{T} 2$ & Useful & Positive & $\begin{array}{l}\text { Increases } \\
\text { combination }\end{array}$ & $\begin{array}{l}\text { Too many } \\
\text { tools }\end{array}$ \\
\hline T3 & Necessary & $\begin{array}{l}\text { More } \\
\text { possibilities }\end{array}$ & $\begin{array}{l}\text { They use the } \\
\text { tools they } \\
\text { want }\end{array}$ & $\begin{array}{l}\text { Why Android, } \\
\text { not all learners } \\
\text { have these } \\
\text { kinds of de- } \\
\text { vices }\end{array}$ \\
\hline $\mathrm{T} 4$ & Good & $\begin{array}{l}\text { Enriches } \\
\text { Learning }\end{array}$ & The same & $\begin{array}{l}\text { How to send } \\
\text { feedback to the } \\
\text { mPLE }\end{array}$ \\
\hline
\end{tabular}

From Table 3, it is possible to conclude that most of the teachers have a positive attitude towards functionality export to the mPLE, which they perceive as useful and that provides a great potentiality to carry out different learning experiences. They also think that the combination of such toots with others used by students for learning is positive and enriches students' learning. In addition, participation may be increased because students can use learning tools on their mobiles, which are devices that they always have at hand. In addition, the mPLE defined in such devices is adapted to students' needs and with it they have available all the tools they really use to learn. Moreover, several of them think that the export of functionalities from the LMS and their combination with other tools may cause a decrease in students' attention, and that maybe students are misled by so many tools in those devices and that it is necessary to define ways to provide feedback to students. In addition, some of the teachers claim that not all students or teachers have Android-based devices.

Furthermore, these conclusions are backed by the results from the quantitative techniques $-70 \%$ of the teachers agree or strongly agree with the exportation of institutional functionalities to mobile devices in order to improve students' participation and enrich institutional learning. The other $30 \%$ believe that it is not easy to have mobile devices involved in all kinds of learning contexts.

The authors of this paper have carried out other experiment with previous framework versions and an HTML5 representation on the mobile of the institutional environment [41]. It considered 40 students from the Project Management subject of the Computer Science degree course of the University of Salamanca. The hypothesis and the assertions of this experiment and the one described in this paper were the same, so it is interesting to compare the results between both of them. To do so, the experimental groups from both pilots are compared. The sample size of this comparison is 43 (23 students from the present experiment and 20 from the previous). As the sample size is around 40, the best test to apply is a Mann-Whitney U test (Table 4). From this table it can be seen that the results for the pretest values have similar ranges and differences are not significant. This means that both groups use the mobile devices in a similar way to learn and to access Moodle. Taking into account the data gathered in the previous section, this means that neither group usually uses their mobile to access Moodle or to learn. 
Table 4. Results for the Mann-Whitney $U$ test comparing both groups. $R_{E}$ is the range for the group in education (present pilot) and $R_{C}$ the range for the group in Computer Science (previous pilot).

\begin{tabular}{lllll}
\hline \multicolumn{5}{c}{ Results of the Mann-Whitney U test (pretest) } \\
\hline DV & $\overline{R_{E}}$ & $\overline{R_{C}}$ & $\bar{U}$ & Signification \\
\hline I1. & 22,17 & 21,80 & 226,000 & 0,920 \\
I2. & 21,52 & 22,55 & 219,000 & 0,777 \\
\hline \multicolumn{5}{l}{ Results of the Mann-Whitney U test (post-test) } \\
\hline I3. & 23,83 & 19,90 & 188,000 & 0,271 \\
\hline
\end{tabular}

Maybe this can be caused because these devices are not adapted to their learning needs and what they carry out there is not taken into account. Also there are no significant differences between the groups after the test (the signification is greater than 0.05), which means that both of them believe that the exportation of functionalities from the institution to the mobile helps them to learn. There is a slight difference in range in I3. This may be because of the different perception the groups involved in the pilots have about the mPLE. There is a difference between using a mobile PLE represented as a single entry point to the learning tools and the institutional functionalities (education pilot), and the need to use a representation of the LMS on the mobile that can be combined with other tools included on the mobile (Computer Science pilot).

\section{Conclusions}

During this paper two main problems have been presented. In current society, learners do not learn just in institutional environments, they learn throughout their whole life, using very different tools and technologies [64] and in very different contexts, and it is necessary to take such learning into account. Nowadays mobile technologies facilitate access to that kind of learning, so it is necessary to take into account what happens on those devices. This can be done through the definition of an mPLE that allows, on the one hand, students to use any application of their device to learn and, on the other, to make visible such learning instances to the institutions.

In order to make this possible, this paper presents a service-based framework approach. This framework, by using interoperability specifications and Web services, makes communication among mobile PLEs and institutional platforms possible.

Such a framework has been implemented as an Android mPLE and tested with students of the University of Salamanca. From this test, it can be concluded that, from the students' perspective and in a controlled context, the opportunity to represent students' PLE on a mobile device that includes functionalities and/or information from the LMS, which could be combined with other tools they use to learn, encourages them to participate in the subjects and helps them to learn.

As a final conclusion, it is possible to say that the implementation of a mobile PLE is a fact and, although the solution can be improved, the key issue is that it can increase students' participation and help them to learn, and it is possible to make some of the mobile learning activities carried out in the MPLE visible to the institution.

As a future work, regarding the framework implementation, it would be interesting to improve the client to support learners' activities logging, and in this way have quantitative data about which are the most used mobile tools for learning; to define new versions of the system for other operative systems; to adapt more tools; to measure the usability of the solution; to compare the grades of the students that use the mobile PLE with others that do not use it, etc. With regard to validation, it is necessary to consider different contexts away from the world of the university, with people with less knowledge about the use of mobiles, in different countries, and to apply other statistical tests and qualitative techniques during the pilots.

\section{Acknowledgements}

This work is partially supported by the Spanish Science and Innovation Ministry through the oiPLE project (ref. TIN2010-21695-C02) and also by the Regional Council of Education of the Junta de Castilla y León through the projects GR47 and MPLE (ref. SA294A12-2). 


\section{Appendix A}

This appendix shows in Table 5 the questionnaire items used during the tests and the questions used to gather students' and teachers' opinions.

Table 5. Measurement instrument: Questionnaire items

\begin{tabular}{|c|c|c|}
\hline \multirow{2}{*}{ Pretest } & I1 & $\begin{array}{l}\text { Sometimes I use my smartphone to access } \\
\text { Moodle and its resources. }\end{array}$ \\
\hline & I2 & $\begin{array}{l}\text { I use my mobile device to learn through } \\
\text { online tools and some mobile applications. }\end{array}$ \\
\hline Post-test & I3 & $\begin{array}{l}\text { The application of online tools, mobile } \\
\text { native applications and Moodle function- } \\
\text { alities on the mobile help me to learn. }\end{array}$ \\
\hline $\begin{array}{l}\text { Additional } \\
\text { opinions from } \\
\text { students }\end{array}$ & Op1 & $\begin{array}{l}\text { After using the Moodle forum through a } \\
\text { mobile device I consider export tools like } \\
\text { those to mobiles make it easy for me to } \\
\text { follow discussions and participate in the } \\
\text { forum, so my learning is improved and the } \\
\text { forum's use is in my opinion more attrac- } \\
\text { tive. }\end{array}$ \\
\hline $\begin{array}{l}\text { Additional } \\
\text { opinions from } \\
\text { teachers }\end{array}$ & Op2 & $\begin{array}{l}\text { The possibility of using institutional tools } \\
\text { in other contexts such as mobile devices } \\
\text { will increase students' participation and } \\
\text { will enrich their learning. }\end{array}$ \\
\hline
\end{tabular}

\section{References}

1. García-Peñalvo FJ (2008) Advances in E-learning: Experiences and methodologies. Information Science Reference (formerly Idea Group Reference). Hershey, PA, USA, Information Science Reference

2. Conde MÁ, García FJ, Rodríguez-Conde MJ, Alier M, Casany MJ, Piguillem J (2014) An evolving learning management system for new educational environments using 2.0 tools. Interactive Learning Environments 22(2):188-204. doi:10.1080/10494820.2012.745433

3. Webb L (2009) The future of higher education: Two contrasting http://www.utahpolicy.com/featured artícle/the-future-higher-education-two-contrasting-viewpoints. Accessed 10 January 2010

4. Conde MÁ, García-Peñalvo FJ, Rodríguez-Conde MJ, Alier M, García-Holgado A (2014) The learners' and teachers' perception of LMS openess in educational and technological areas. Computers in Human Behaviour 31:517-526

5. Prendes MP (2009) Plataformas de campus virtuałes de Software Libre: Análisis compartivo de la situación actual de las Universidades Españoles. Informe del proyecto EA-2008-0257 de la Secretaría de Estado de Universidades e Investigación

6. Wexler S, Dublin L, Grey N, Jagannathan S, Karrer T, Martinez M, Mosher B, Oakes K, Barneveld Av (2008) Learning management systems. The good, the bad, the ugly,... and the truth. Guild Research 360 Degree Report. The eLearning Guild

7. Avgeriou P, Papasalouros A, Retalis S, Skordalakis M (2003) Towards a pattern language for learning management systems. Educational Technology \& Society $6(2): 11-24$

8. Downes S (2005) E-learning 2.0. Elearn magazine 2005 (10):1. doi:10.1145/1104966.1104968

9. Wesch M (2009) From knowledgable to knowledge-able: Learning in New Media Environments http://www.academiccommons.org/2009/01/from-knowledgable-to-knowledge-able/\#more-470. Accessed 19 January 2014

10. Adell J, Castañeda L (2010) Los Entornos Personales de Aprendizaje (PLEs): Una nueva manera de entender el aprendizaje. In: Roig Vila R, Fiorucci M (eds) Claves para la investigación en innovación y calidad educativas. La integración de las Tecnologías de la Información y la Comunicación y la Interculturalidad en las aulas. Stumenti di ricerca per l'innovaziones e la qualità in ámbito educativo. La Tecnologie dell'informazione e della Comunicaziones e l'interculturalità nella scuola. Marfil - Roma TRE Universita degli studi, Alcoy, Spain

11. ITU (2012) Measuring the information society. International Telecommunication Union, Geneva, Switzerland

12. Buchem I, Attwell G, Torres R (2011) Understanding personal learning environments: Literature review and synthesis through the Activity Theory lens. Paper presented at the The PLE Conference 2011, Southampton, UK

13. Conde MÁ, García-Peñalvo FJ, Alier M (2011) Interoperability scenarios to measure informal learning carried out in PLEs. Paper presented at the Third IEEE International Conference on Intelligent Networking and Collaborative Systems, IEEE INCoS 2011, Fukuoka, Japan

14. Pettit J, Kukulska-Hulme A (2007) Going with the grain: Mobile devices in practice. Australian Journal of Educational Technology - AJET 23(1):17-33

15. Jenkins H, Purushotoma R, Clinton KA, Weigel M, Robison AJ (2006) Confronting the challenges of participatory culture: Media education for the 21st century. http://files.eric.ed.gov/fulltext/ED536086.pdf. Accessed 19 January 2014.

16. Attwell G, Cook J, Ravenscroft A (2009) Appropriating technologies for contextual knowledge: Mobile personal learning environments. Paper presented at the Second World Summit on the Knowledge Society, WSKS, Crete, Greece

17. Sharples M (2000) The design of personal mobile technologies for lifelong learning. Comput Educ doi:10.1016/s0360-1315(99)00044-5 
18. Whalley WB, France D, Park JR, Welsh K, Favis-Mortlock D (2011) Flexible personal learning environments, developed with netbook computers, to enhance learning in fieldwork learning spaces. Paper presented at the The PLE Conference 2011, Southampton, UK

19. Sha L, Looi CK, Chen W, Zhang BH (2012) Understanding mobile learning from the perspective of self-regulated learning. Journal of Computer Assisted Learning doi:10.1111/j.1365-2729.2011.00461.x

20. Ignatko I, Zielasko D (2011) Mobile personal learning environments. Paper presented at the Seminar: Mobile Learning

21. van Harmelen M (2006) Personal learning environments. Paper presented at the Proceedings of the Sixth IEEE International Conference on Advanced Learning Technologies, Kerkrade, The Netherlands

22. Sharples M, Corlett D, Westmancott O (2002) The design and implementation of a mobile learning resource. Personal Ubiquitous Comput doi: $10.1007 / \mathrm{s} 007790200021$

23. Götzelt K-U, Bodendorf F (2008) Personal learning environments on mobile devices. Paper presented at the IADIS International Conference on Cognition and Exploratory Learning in Digital Age (CELDA 2008), Freiburg, Germany

24. Cook J (2010) Longitudinal, educational design research investigation of the temporal nature of learning: Taking a Vygotskian approach. Journal of Interactive Media in Education (11):1-20

25. Thüs H, Akbari M, Schroeder U (2011) Mobile personal environment for higher education. Paper presented at the PLE Conference 2011, Southampton, UK

26. Perifanou M (2010) Using iphone as my "personal mobile language learning environment": An exploration and classification of language learning possibilities. Paper presented at the PLE Conference 2010, Barcelona, Spain

27. Molly (2010) Molly Project - The open source mobile portal. http://mollyproject.org/. Accessed 19 January 2014

28. Jennings T (2011) Technology audit - CampusM. Ovum's Knowledge Centers.

29. Razavi MN, Iverson L (2006) A grounded theory of information sharing behavior in a personal learning space. Paper presented at the Proceedings of the 2006 20th anniversary conference on Computer Supported Cooperative Work, Banff, Alberta, Canada

30. Gillet D, Law ELC, Chatterjee A (2010) Personal learning environments in a global higher engineering education Web 2.0 realm. In: Education Engineering (EDUCON), IEEE, 14-16 April 2010 pp 897-906. doi:10.1109/EDUCON.2010.5492483

31. Aplix-Corporation (2009) Aplix web runtime. http://wiki.webvm.net/wrtc/. Accessed 20 April 2012 $\begin{array}{ccccc}\text { DEV.OPERA } & \text { (2011) } & \text { Widget } & \text { runtime: } & \text { WAC-1.0-compliant Golden } \\ \text { http://dev.opera.com/articles/view/labs-widget-runtime-wac-1-0-compliant-golden-for-android/. Accessed 19 January 2014 }\end{array}$

33. Sachse J (2010) The standardization of widget-APIs as an approach for overcoming device fragmentation. GRIN Verlag GmbH.

34. Pratt J, Hinkelman D, Bateson G, Gettings B, Sekiya N, Takemoto T (2006) Moodle for Mobile. http://docs.moodle.org/en/Moodle_for_Mobiles. Accessed 19 January 2014.

35. Yingling M (2006) Mobile Moodle. Journal of Computing Sciences in Colleges 21(6):280-281

36. Alier M, Casany M (2008) Moodbile: Extending Moodle to the mobile on/offline scenario. Paper presented at the IADIS International Conference Mobile Learning, April 2008, Algarve, Portugal

37. Conde MÁ, Muñoz C, García FJ (2008) Sistemas de adaptación de contenidos para dispositivos móviles. Paper presented at the Actas del Congreso de IX Congreso Internacional de Interacción Persona - Ordenador, Albacete

38. Meisenberger M, Nischelwitzer A (2004) The mobile learning engine (MLE) - A mobile, computer-aided, multimedia-based learning application. Paper presented at the Multimedia Applications in Education Conference, MApEC'04, Austria

39. Casany MJ, Conde MÁ, Alier M, García F (2009) Applications of service oriented architecture for the integration of LMS and m-learning applications. Paper presented at the Fifth International Conference on Web Information Systems and Technologies - WEBIST 2009, Lisboa

40. Sakai (2011) Google Summer of 2011. https://confluence.sakaiproject.org/display/MGT/Google+Summer+of+Code+2011+ideas+list\#GoogleSummerofCode2011ideaslist-. Accessed 19 January 2014

41. Conde MÁ, García-Peñalvo FJ, Alier M, Piguillem J (2013) The implementation, deployment and evaluation of a mobile personal learning environment. Journal of Universal Computer Science 19(7):854

42. Vavoula G, Sharples M (2009) Meeting the challenges in evaluating mobile learning: A 3-level evaluation framework. IGI Global. doi:10.4018/jmbl.2009040104

43. Perry NE, Winne PH (2006) Learning from learning kits: gStudy traces of students' self-regulated engagements with computerized content. Educ Psychol Rev doi:10.1007/s10648-006-9014-3

44. Winne P, Jamieson-Noel D, Muis K (2002) Methodological issues and advances in researching tactics, strategies, and self-regulated learning. Advances in motivation and achievement: New directions in measures and methods doi:citeulike-article-id:12391545

45. Wilson S, Sharples P, Griffiths D (2008) Distributing education services to personal and institutional systems using widgets. Paper presented at the Mash-Up Personal Learning Environments - Ist Workshop MUPPLE'08, Maastricht, The Netherlands

46. Casquero O, Portillo J, Ovelar R, Romo J, Benito M (2008) iGoogle and gadgets as a platform for integrating institutional and external services. Paper presented at the Mash-Up Personal Learning Environments - 1st Workshop MUPPLE'08, Maastricht, The Netherlands

47. Torres R, Edirisingha P, Mobbs R (2008) Building Web 2.0-based personal learning environments: A conceptual framework. Paper presented at the EDEN Research Workshop 2008, Paris, France

48. IMS-GLC (2011) Common cartridge and basic learning tools interoperability progress and conformance status http://www.imsglobal.org/cc/statuschart.html. Accessed 19 January 2014

49. Peret Y, Leroy S, Leprêtre E (2010) First steps in the integration of institutional and personal learning environments. Paper presented at the Workshop Future Learning Landscape - EC-TEL 2010, 28 September 2010, Barcelona, Spain

50. Taraghi B (2012) Ubiquitous personal learning environment (UPLE). In: 15th International Conference on Interactive Collaborative Learning (ICL), 2012, 26-28 Sept. pp 1-8. doi:10.1109/ICL.2012.6402139

51. OMG (2011) Business process model and notation - version 2.0. http://www.omg.org/spec/BPMN/2.0/PDF/. Accessed 28 May 2013

52. MoodleStats (2014) Moodle stats. http://moodle.org/stats. Accessed 19 January 2014

53. Cole J, Foster H (2007) Using Moodle. 2 edn. O’Really

54. Molist M (2008) Moodle llena la geografía educativa española de campus virtuales. Diario el Pais. http://www.elpais.com/articulo/portada/Moodle/llena/geografia/educativa/espanola/campus/virtuales/elpeputec/20081204elpcibpor 1/Tes. Accessed 19 January 2014

55. Casany MJ, Alier M, Conde MÁ, García FJ (2009) SOA Initiatives for eLearning: A Moodle case. Paper presented at the 23rd International Conference on Advanced Information Networking and Applications, AINA, May 26-29, 2009, Bradford, United Kingdom

56. Conde MÁ, Gómez DA, Pozo Ad, García-Peñalvo F (2010) Web services layer for Moodle 2.0.: A new area of possibilities in web based learning. International Journal of Technology Enhaced Learning (IJTEL) 3:308-321

57. IMS-GLC (2010) Basic learning tools interoperability http://www.imsglobal.org/lti/blti/bltiv1p0/ltiBLTIimgv1p0.html. Accessed 19 January 2014

58. W3C (2011) HTML5. A vocabulary and associated APIs for HTML and XHTML. http://www.w3.org/TR/html5/. Accessed 19 January 2014. 
García-Peñalvo, F. J., \& Conde, M. Á. (2015). The impact of a mobile Personal Learning Environment in different educational contexts. Universal Access in the Information Society, 14(3), 375-387. doi:10.1007/s10209-014-0366-z

59. Casany MJ, Alier M, Mayol E, Piguillem J, Galanis N, García-Peñalvo FJ, Conde MÁ (2012) Extending Moodle services to mobile sevices: The Moodbile Project. Paper presented at the UBICOMM 2012: The Sixth International Conference on Mobile Ubiquitous Computing, Systems, Services and Technologies, Barcelona, Spain

60. Green JL, Camilli G, Elmore PB (2006) Handbook of complementary methods in education research. American Educational Research Association by Lawrence Erlbaum Associates, Inc.

61. Campbell DT, Stanley JC (1963) Experimental and quasi-experimental designs for research. Rand McNally

62. Siegel S (1956) Nonparametric statistics for the behavioral sciences. McGraw-Hill

63. Miles MB, Huberman AM (1994) Qualitative data analysis: Anexpanded sourcebook. Sage Publications

64. Berlanga AJ, García-Peñalvo FJ, Sloep PB (2010) Towards eLearning 2.0 university. Interactive Learning Environments doi: $10.1080 / 10494820.2010 .500498$

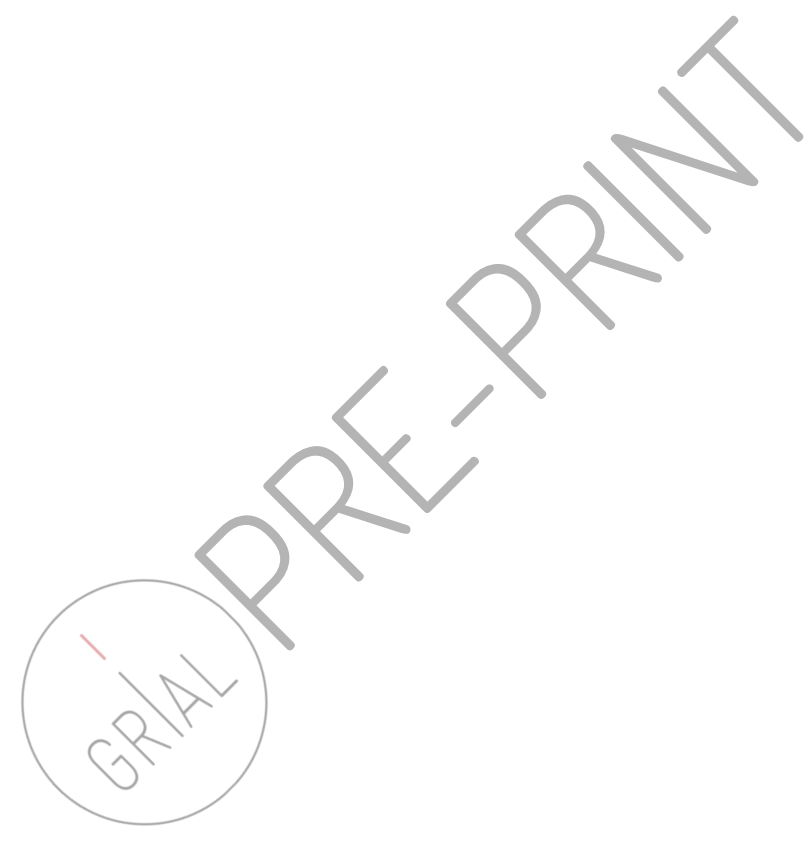

